\title{
Pioglitazone Confers Neuroprotection Against Ischemia-Induced Pyroptosis due to its Inhibitory Effects on HMGB-1/RAGE and Rac1/ROS Pathway by Activating PPAR- $\gamma$
}

\author{
Pingping Xia Yundan Pan Fan Zhang Na Wang E Wang Qulian Guo Zhi Ye \\ Department of Anesthesiology, Affiliated Xiangya Hospital of Central South University, Changsha, \\ Hunan Province, China
}

\author{
Key Words \\ Pioglitazone $\cdot$ Cerebral ischemia $\cdot$ Pyroptosis $・$ PPAR- - HMGB-1/RAGE • Rac1
}

\begin{abstract}
Background/Aims: Recent researches highlighted the protective potential of pioglitazone, a PPAR- $\gamma$ agonist, in the progression of cerebral ischemia-reperfusion injury. However, there has been no study on the application of pioglitazone in treating ischemic stroke through mechanisms involving pyroptosis. Methods: The cerebral injury was established by middle cerebral artery occlusion (MCAO). in vitro ischemia in primary cultured astrocytes was induced by the oxygen-glucose deprivation (OGD). ELISA and Western Blot analysis were employed to the levels of PPAR- $\gamma$, pyroptosis-related biomarkers and cytoplasmic translocation of HMGB1 and RAGE expression as well as Rac1 activity, respectively. Results: We demonstrated that repeated intraperitoneal administration of pioglitazone remarkably reduced the infarct volume, improved neurological deficits and suppressed the Rac1 activity with significant reduction of excessive ROS in rat model of middle cerebral artery occlusion (MCAO). Moreover, pioglitazone alleviated the up-regulation of pyroptosis-related biomarkers and the increased cytoplasmic translocation of HMGB-1 and RAGE expression in cerebral penumbra cortex. Similarly, the protective effects of pioglitazone on cultured astrocytes were characterized by reduced Rac1 activity, pyroptosis related protein expressions and lactate dehydrogenase $(\mathrm{LDH})$ release. However, these protective effects of pioglitazone were neutralized with the use of GW9662, a PPAR-r inhibitor. Interestingly, Rac1 knockdown in lentivirus with the Rac1 small hair RNA (shRNA) could inhibit the OGD-induced pyroptosis of primary cultured astrocytes. Furthermore, the combination of Rac1-shRNA and pioglitazone can further strengthen the inhibitory effects on pyroptosis induced by OGD. Conclusion: The neuroprotection of pioglitazone was attributable to the alleviated ischemia/hypoxia-induced pyroptosis and was also associated with the PPARr-mediated suppression of HGMB-1/RAGE signaling pathway. Moreover, the inhibition of Rac1 promoted this function.

(C) 2018 The Author(s) Published by S. Karger AG, Basel




\section{Cellular Physiology Cell Physiol Biochem 2018;45:2351-2368 \\ and Biochemistry Published onIIne: IVarch 16, 2018 \begin{tabular}{l|l} 
DOI: 10.1159/000488183 2018 The Author(s). Published by S. Karger AG, Basel \\
www.karger.com/cpb
\end{tabular} \\ Xia et al.: Pioglitazone Protected Against Pyroptosis by Activating PPAR- $\gamma$}

\section{Introduction}

Perioperative stroke caused by cerebral ischemia or cerebral hemorrhage can happen during the surgery operation or 3 to 30 days after surgery $[1,2]$. With the aging society in China, the incidence and mortality of perioperative stroke are getting higher and higher, leading to huge economic and emotional losses to the society and patients' families.

Growing evidence showed that inflammatory response plays a crucial role in the progression of neuronal loss and ischemia brain injury [3, 4]. Pyroptosis, a unique caspase1-dependent programmed cell death, is associated with the release of inflammatory cytokines, making pyroptosis morphologically and mechanistically different from apoptosis and necrosis. Several studies have indicated that pyroptosis was a major cause of infectious disease, nervous system disorders, and atherosclerosis [5-7].

NOD-like receptor protein 3 (NLRP3) inflammasome, a multiprotein complex, consists of NLRP3, ASC (apoptosis-associated speck-like protein containing a CARD), and procaspase-1, and can turn on the inflammatory response. Numerous studies have indicated that NLRP3 inflammasome plays a big role in the development of pyroptosis [8, 9]. Its activation by danger signals can mediate the maturation of capase- 1 , which results in the conversions of precursors of interleukin-1 $\beta$ and 18 into their active forms [10]. Recent researches further demonstrated that pyroptosis mediated the death of renal tubule epithelial cells after renal ischemia reperfusion injury $[11,12]$. Therefore, it is of great significance to understand the mechanism that suppresses the inflammatory response and is responsible for the pyroptosis inhibition during the development and progression of cerebral ischemia injury.

Peroxisome proliferator activated receptors (PPARs) belong to the nuclear receptor super family. The PPAR- $\gamma$ isoform plays an important role in attenuating neurodegenerative and inflammatory processes in the brain $[13,14]$. Recent data from animal experiments demonstrated that PPAR- $\gamma$ agonists confer neuroprotection and neurological improvement following cerebral ischemia [15-18]. Moreover, In the clinic practice, PPAR- $\gamma$ ligand pioglitazone reduced the incidence of stroke in patients with type 2 diabetes [19]. The neuroprotection observed after treatment with PPARs agonists is related to several mechanisms including both oxidative stress modulation and anti-inflammatory effect. Pioglitazone is able to decrease inflammatory responses, by the mechanisms involved in inhibition of the nuclear transcription factor kappa B (NF-kB) p65 monomer as well as induction of $\mathrm{I} \kappa \mathrm{B} \alpha$ (inhibitory $\kappa \mathrm{B}$ ) [15]. Furthermore, the role of suppression of activation of p38 mitogen activated protein kinase (MAPK) has also been demonstrated recently [16]. Importantly, down-regulating cyclooxygenase-2 (COX-2) and inducible nitric oxide synthase (iNOS) expression, PPAR- $\gamma$ agonists affect the generation of reactive oxygen species (ROS) $[17,18]$.

Neurons localized in the ischemia core die rapidly after cerebral ischemia because of dramatic reduction of local cerebral blood flow, which is characterized by the high production of ROS. Excessive ROS production also promotes the accumulation and activation of proinflammatory cytokines in ischemia area [20]. Therefore, substances that can antagonize these harmful effects induced by surplus ROS may play a promising and neuroprotective role in stroke treatment. Ras-related C3 botulinum toxinsubstrate l (Rac1), a small GTPase protein, is an essential subunit of NADPH oxidase for the generation of ROS [21]. Moreover, Rac1 inhibition provides notable neuroprotective effects in the normal or diabetic brains by inhibiting ROS production [22-24]. Nevertheless, whether pioglitazone relieves ROS production by inhibiting Rac1 activation and the role of Rac1 in pyroptosis has not yet been fully elucidated.

High-mobility group protein 1 (HMGB-1), an important damage-associated molecular pattern (DAMP), was reported to be released into the extracellular space from necrotic and dying neural cells in the ischemic brain, triggering neuroinflammation and microglial activation [25]. Once HMGB-1 is released from cell into extracellular space, it can bind to the receptor for advanced glycation end products (RAGE), resulting in the activation of MAPK [26] and NF-KB signaling pathways [27]. It is well accepted that up-regulation of HMGB-1/ 


\section{Cellular Physiology Cell Physiol Biochem 2018;45:2351-2368 \begin{tabular}{l|l} 
and Biochemistry Published 10.1159/000488183 & $\begin{array}{l}\text { D) } 2018 \text { The Author(s). Published by S. Karger AG, Basel } \\
\text { www.karger.com/cpb }\end{array}$ \\
\hline
\end{tabular}}

Xia et al.: Pioglitazone Protected Against Pyroptosis by Activating PPAR- $\gamma$

RAGE controls the initiation and development of the underlying inflammatory reaction [28]. Therefore, blocking the HMGB-1/RAGE signaling pathway is an effective way to treat the inflammatory injury from stroke.

In this study, we investigated whether the novel neuroprotective effect of PPAR- $\gamma$ ligand pioglitazone on transient middle cerebral artery occlusion (MCAO) and cultured primary astrocytes was involved in pyroptosis-related inflammatory response and whether the blockade of HMGB-1/RAGE signaling pathway was involved in the underlying molecular mechanism. In addition, we further tested the hypothesis that pioglitazone could alleviate pyroptosis by inhibiting Rac1 activity in vivo and in vitro.

\section{Materials and Methods}

All experiments were carried out in accordance with the standards and procedures of the Chinese Council on Animal Care and were approved by the Institutional Animal Care and Use Committee in Central South University.

\section{Material preparation and treatment schedule}

Pioglitazone was obtained from Takeda Pharmaceuticals North America (Chicago, IL) and dissolved in DMSO. All male Sprague Dawley rats were randomly assigned into four groups: (1) Sham group (S): rats underwent the same surgical procedure without ischemia; (2) MCAO group (M): rats were subjected to right middle cerebral artery occlusion (MCAO) for $90 \mathrm{~min}$, followed by reperfusion for three days. (3) Pioglitazone group (P): rats received repeated intraperitoneal administration of pioglitazone $(10 \mathrm{mg} / \mathrm{kg})$ daily for three days. After the drug treatment, rats underwent MCAO. (4) Vehicle group (V): rats received repeated intraperitoneal administration of the same volume of DMSO daily for three days before the rats took MCAO by the suture method as described previously [22]. Briefly, a midline neck incision was made to expose the right common carotid artery. The external carotid and occipital arteries were ligated with 4-0 silk suture and an incision was made in the wall of the external carotid artery close to the bifurcation point of the external and internal carotid arteries. A 4-0 heat-blunted nylon suture (Ethicon) was inserted and advanced $18 \mathrm{~mm}$ from the bifurcation point into the internal carotid arteries. After the 90-min occlusion, the nylon suture was removed to allow the reperfusion of blood flow into the MCA.

\section{Cerebral blood flow}

To ensure the induction of ischemia by MCAO, regional cerebral blood flow ( $\mathrm{rCBF}$ ) was monitored using laser Doppler flowmetry (LDF, PeriFlux System 5, 000, PERINMED). Two cortical regions were measured: the ipsilateral ischemia parietal cortex and the contralateral non-ischemia parietal cortex. In brief, each animal was mounted in a stereotaxic frame. Under microscopic guidance, two burr holes ( $1 \mathrm{~mm}$ in diameter) were drilled with the following coordinates: $0.5 \mathrm{~mm}$ anterior and $5.0 \mathrm{~mm}$ lateral. Then, LDF probes (PROBE 403 , Fiber separation $=0.25 \mathrm{~mm}$ ) were placed on each cortical region with a micromanipulator. Blood flow was measured ( $2 \mathrm{~Hz}$ sampling rate) before, during, and up to 60 minutes after MCAO respectively.

\section{Determination of infarct volume and neurological deficit}

Three days after reperfusion, rats ( $n=6-8$, per group) were decapitated and brains were removed. Infarct sizes were measured by staining the tissues with 2, 3, 5-triphenyltetrazolium chloride (TTC). A previously reported equation was used with slight modification to eliminate the contribution of edema to the ischemic lesion: corrected infarct volume $=$ contralateral hemisphere volume- (ipsilateral hemisphere volume - measured infarct volume) $[22,29]$. The infarct volume was presented as the percent of total brain area.

Neurological deficits were measured on days 1 and 3 after reperfusion respectively according to the method reported by Longa et al. [30]. Neurological findings were reported on a 5-point scale. No neurological deficit $=0$, failure to extend right paw fully $=1$, circling to right $=2$, falling to right $=3$, No spontaneously walking or depressed levels of consciousness $=4$.

\section{Histological examination}

After 3 days of reperfusion, the rats were perfusionfixed with $4 \%$ paraformaldehyde in $0.1 \mathrm{M}$ phosphate buffer (pH7.4) under anesthesia. The paraffin-embedded brain sections $(5 \mu \mathrm{m})$ were prepared and stained 


\section{Cellular Physiology Cell Physiol Biochem 2018;45:2351-2368 \begin{tabular}{l|l} 
and Biochemistry Published onIIne:IVarch 16, 2018 & $\begin{array}{l}\text { D) } 2018 \text { The Author(s). Published by S. Karger AG, Basel } \\
\text { www.karger.com/cpb }\end{array}$ \\
\hline
\end{tabular}}

Xia et al.: Pioglitazone Protected Against Pyroptosis by Activating PPAR- $\gamma$

with hematoxylin and eosin. Histological evaluations were performed with HE-staining for assessing neuronal damage in the penumbra of ischemic cortex. In order to observe cell morphology, the pathological sections were observed under light microscopy (Leica Microsystems) at $400 \times$ amplified.

Apoptotic cells in brain tissue sections were identified by in situ cell death detection kit (Roche Company, Basel, Switzerland) as described previously [29]. Sections were photographed using a light microscope (IX81; Olympus). Positive neurons were counted using Image Pro Plus 6.0 (Media Cybernetics, Silver Spring, MD, USA). Coded slides were initially examined for the presence TUNEL-positive cells in the penumbra region by an examiner blind to the group assignment of each animal. TUNEL-positive apoptotic cells exhibited brown nuclear or cytoplasmic staining. The number of TUNEL-positive neurons and total neurons in the penumbra region was counted in 3 different fields for each section at $\times 200$ magnification. The total number of TUNEL-positive neurons and total neurons found in the 5 selected sections of penumbra region was calculated, and mean number of cells per section was used for comparison. The extent of apoptosis was also calculated and expressed as a ratio of TUNEL-positive neurons versus total neurons.

\section{Isolation and cultured primary astrocytes}

Cerebral astrocytes were taken from neonatal Sprague-Dawley rats as previously described with slight modifications [31]. Briefly, neonatal rats on postnatal day 1 (P1) were anaesthetized with $2 \%$ isoflurane and the cortex was dissected and digested with $0.125 \%$ trypsin for $30 \mathrm{~min}$ at $37^{\circ} \mathrm{C}$. Cells were placed on dishes containing $0.0125 \%$ poly-L-lysine-coated culture in Neurobasal medium (Gibco, USA) with B27 (Gibco, USA) and were incubated in a humidified atmosphere with $5 \% \mathrm{CO}_{2}$ at $37{ }^{\circ} \mathrm{C}$.

After the 10-day incubation, astrocytes for oxygen-glucose deprivation (OGD) were grown on 96-well plates at a density of $1 \times 10^{5}$ cells per well. Cells in control group were not subjected to OGD. OGD media was made of glucose-free DMEM (5\% HS, $2 \mathrm{mM}$ glutamine and 1\% penicillin/streptomycin) and subsequently bubbled with gas mixture of $95 \%$ nitrogen and $5 \% \mathrm{CO}_{2}$ for 15 minutes. The cells were then washed twice with OGD media and placed in an anoxic incubator for 2 hours $\left(95 \% \mathrm{~N}_{2}\right.$ and $\left.5 \% \mathrm{CO}_{2}\right)$. The incubated cells were randomly divided into following groups: (1) Control group (normal condition): cells were cultured for $27 \mathrm{~h}$ in culture medium without OGD. (2) OGD group: cells were subjected to OGD for 2h; (3) OGD+Pio group: cells were treated with pioglitazone $(10 \mu \mathrm{M})$ dissolved in DMSO 1h prior to OGD, subsequently suffered from OGD for two hours. Then the OGD medium was replaced with the original culture and the resulted cells were incubated for $24 \mathrm{~h}$ in humidified atmosphere with $5 \% \mathrm{CO}_{2}$ at $37{ }^{\circ} \mathrm{C}$. (4) OGD+ Vehicle group: the same volume of DMSO was used to replace the pioglitazone solution. (5) OGD+GW9662: cells were treated with GW9662 $(10 \mu \mathrm{M}) 1 \mathrm{~h}$ prior to OGD, and subsequently suffered from OGD for two hours. Then, the OGD medium was replaced with the original culture and the cells were incubated for $24 \mathrm{~h}$ in humidified atmosphere with $5 \% \mathrm{CO}_{2}$ at $37{ }^{\circ} \mathrm{C}$. (6) OGD+GW9662+Pio: cells were co-treated with GW9662 + pioglitazone prior to OGD, and subsequently suffered from OGD for two hours. (7) OGD+Rac1-shRNA/misRNA: cells were infected with Rac1 shRNA lentivirus or misRNA $(1 \mu \mathrm{l} / \mathrm{ml}$ of media) for 24 hours before the medium was replaced with fresh medium. Successful infection was confirmed using the GFP reporter. Plates were not used unless more than $80 \%$ of cells expressed GFP. (8) OGD+Rac1-shRNA+Pio: the astrocytes were transduced with the lentivirus according to the manufacturers' instruction. The OGD model and pioglitazone treatment were carried out $6 \mathrm{~d}$ after transduction.

\section{Cell survival assays}

Survived cells were counted with the cell counting kit-8 (CCK-8) (Dojindo, Japan) according to the manufacturer's instructions. Briefly, the treated neurons were loaded into 96-well plates and replenished with $100 \mu$ l fresh DMEM medium (Gibco, USA) before $10 \mu$ l CCK- 8 solution was added to each well. After incubated at $37{ }^{\circ} \mathrm{C}$ for $2 \mathrm{~h}$, survived cells were determined by optical absorption at $450 \mathrm{~nm}$. The ratio of survived cells in each group has to be normalized to the amount of control (normal condition) group, which the ratio of survived cells is represent as $100 \%$.

\section{Measurement of ROS generation}

The productions of intracellular ROS was measured using Reactive Oxygen Species Assay Kit (Beyotime) and MitoSOXTM Red (Molecular Probes, Eugene, OR, USA) according to the manufacturer's protocols. After the appropriate treatments, neurons were washed twice with PBS and incubated in DCFH-DA (Sigma, USA) at $37{ }^{\circ} \mathrm{C}$ for $30 \mathrm{~min}$ to reach a final concentration of $10 \mu \mathrm{M}$. Fluorescence was measured at an excitation 


\section{Cellular Physiology Cell Physiol Biochem 2018;45:2351-2368 \\ \begin{tabular}{l|l} 
and Biochemistry Published online: March 16, 2018 & $\begin{array}{l}\text { (c) } 2018 \text { The Author(s). Published by S. Karger AG, Basel } \\
\text { www.karger.com/cpb }\end{array}$
\end{tabular}}

Xia et al.: Pioglitazone Protected Against Pyroptosis by Activating PPAR- $\gamma$

wavelength of $485 \mathrm{~nm}$ and an emission wavelength of $530 \mathrm{~nm}$ using a fluorescent plate reader (Genios, Tecan). Higher fluorescence intensity meant an increase in intracellular ROS. Similarly, the level of increased ROS production in each group also has to be normalized to the amount of control (normal condition) group, which the level of ROS is represent as $100 \%$.

\section{Measurement of $I L-1 \beta$ and $I L-18$ productions}

The levels of IL-1 $\beta$ and IL-18 in neurons were determined by ELISA assays (ab100768 for IL-1 $\beta$ and ab213909 for IL-18, Cambridge, Abcam, UK) according to the manufacturer' instructions. The quantities of IL-1 $\beta$ and IL-18 were measured using a microplate reader at $450 \mathrm{~nm}$.

Lactate dehydrogenase release assay

The release of lactate dehydrogenase (LDH) into the culture media is an indicator of cytotoxicity. The method was described previously [32]. Briefly, after the cells went through all above procedures, samples of the culture supernatant were taken, and LDH levels in those samples were determined using the LDH cytotoxicity detection kit (Roche, Basel, Switzerland) according to the manufacturer's instructions. The absorbance of samples at $490 \mathrm{~nm}$ was measured using a microplate reader (Tecan).

\section{ELISA Examination of Plasma HMGB-1}

The rats were sacrificed $3 \mathrm{~d}$ after ischemia, and blood samples obtained from the inferior vena cava were stored in Vacuette blood collection tubes containing heparin. The plasma HMGB-1 concentrations were determined using a commercial enzyme-linked immunosorbent assay (ELISA) kit (SHINO-TEST, Japan) according to the manufacturer's protocol.

\section{Immunofluorescent staining}

The primary astrocytes cultured on coverslips were fixed with cold methanol $\left(-20^{\circ} \mathrm{C}\right)$ for 5 min and subsequently incubated with 10\% normal goat serum for $120 \mathrm{~min}$. Cells were then incubated with a rabbit polyclonal antibody against the a rabbit polyclonal antibody against HMGB-1 (1:100, ab195011, Abcam Cambridge, UK) as the primary antibody at $4{ }^{\circ} \mathrm{C}$ overnight. After washing with PBS, the cells were incubated for $2 \mathrm{~h}$ with FITC-conjugated goat anti-rabbit IgG antiserum (1:200, Chemicon, USA) and examined under a fluorescence microscope (Olympus X51).

\section{Preparation of Cytosol and Nuclear Extracts}

Cytosol and nuclear were extracted using the method reported in our previous study [33]. Frozen samples were homogenized in $800 \mu \mathrm{l}$ buffer A (10 mM Hepes-KOH, pH 7.9, $10 \mathrm{mM} \mathrm{KCl,} 0.1 \mathrm{mM}$ EDTA, 0.1 mM EGTA, 1 mM dithiothreitol (DTT), $1 \mathrm{mM}$ phenylmethylsulfonyl fluoride (PMSF), $2 \mu \mathrm{g} / \mathrm{mL}$ pepstatin A, 1 $\mu \mathrm{g} / \mathrm{ml}$ leupeptin, and $100 \mathrm{nM}$ calyculin $\mathrm{A}$ ) at $4^{\circ} \mathrm{C}$. The mixture was kept on ice for 15 minutes before $50 \mu \mathrm{l}$ of $1 \%$ Nonidet P-40 was added and the mixture was vortexed. The homogenate was centrifuged for 5 minutes at $10,000 \times \mathrm{g}$ at $4^{\circ} \mathrm{C}$ Supernatant containing cell extracts was transferred to a fresh tube and crude nuclear pellets were resuspended in $50 \mu \mathrm{l}$ ice-cold buffer C (20 mM Tris- $\mathrm{HCl}, \mathrm{pH}$ 7.5, $400 \mathrm{mM} \mathrm{NaCl}, 0.1 \mathrm{mM}$ EDTA, 0.1 mM EGTA, 1 mM DTT, 1 mM PMSF, 2 lg/ml pepstatin A, $100 \mathrm{nM}$ calyculin A). The nuclear pellet suspension was incubated on ice for $30 \mathrm{~min}$ and then centrifuged for $10 \mathrm{~min}$ at $10,000 \times \mathrm{g}$ at $4^{\circ} \mathrm{C}$. Supernatant with nuclear proteins was collected for the following research.

\section{Western blot analysis}

The expressions of proteins extracted from the primary astrocytes and the right cerebral cortex of rats were analyzed by Western blot. Proteins in the samples were separated on a $12 \%$ sodium dodecyl sulfate (SDS)/polyacrylamide gel and transferred onto polyvinylidene fluoride membranes (Millipore, USA). The membranes were incubated with the primary antibodies including anti-caspase-1 (1:500, ab108362, Abcam Cambridge, UK); anti-NLRP3 (1:1, 000; Cryo-2, AdipoGen); anti-ASC (N-15) (1:1, 000; Santa Cruz), anti-HMGB-1 (1:500, ab79823, Abcam Cambridge, UK), anti-RAGE (1:500, ab181293, Abcam Cambridge, UK), PPAPr (1: 1000, ab41928, Abcam Cambridge, UK), GAPDH (1:5000, \#5014, Cell Signaling Technology, USA) and Histone H3 (1:1000, \#12648, Abcam Cambridge, UK, loading control for nuclear proteins) at $4{ }^{\circ} \mathrm{C}$ overnight. Immuno-reactive bands were visualized by increased chemiluminescence (Millipore, USA) using corresponding horseradish peroxidase-conjugated IgG secondary antibodies (Cell Signaling Technology, USA). The images were captured with the gel imager (UVITEC, UK) and quantified using Quantity One software (Bio-Rad, USA). 


\section{Cellular Physiology Cell Physiol Biochem 2018;45:2351-2368

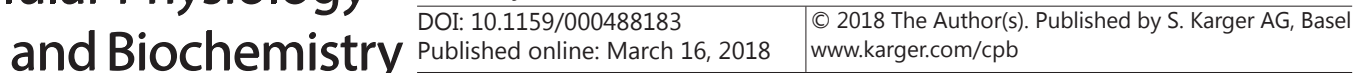 \\ Xia et al.: Pioglitazone Protected Against Pyroptosis by Activating PPAR- $\gamma$}

Rac1 activation assay

Rac1-GTP pulldown and the activation assay were performed using the Rac1 activation assay kit (Cell Biolabs) and the secondary antibodies described above. Fresh tissues and the cultured primary astrocytes were homogenized in $1 \mathrm{ml}$ ice-cold $1 \times$ assay/lysis buffer, while the rest procedures followed the manufacturer's instructions reported in our previous study [34].

\section{Statistical analysis}

All data were analysed with GraphPad PRISM 5.0 (GraphPad sofware, USA) software using the Student's t-test or one-way ANOVA followed by Tukey-Kramer tests. All quantitative values were expressed as the mean \pm SD. Differences were deemed signifcant when $P<0.05$.

\section{Results}

Physiological parameters and cerebral blood flow (CBF)

No significant discrepancy in $\mathrm{pO}_{2}$, $\mathrm{pCO}_{2}$, or blood $\mathrm{pH}$ was noted in ischemic rats treated with or without pioglitazone. Body and brain temperatures remained at approximately $37^{\circ} \mathrm{C}$ throughout the course of the experiments. No hypothermic action was observed (Table-1).

Moreover, we used laser-Doppler flow (LDF) to measure cerebral blood flow (CBF) to exclude the possibility that different residual $\mathrm{CBF}$ might cause the difference in infarct volume during and after ischemia . Immediately after ischemia, CBF dropped to approximately $15 \%$ of baseline in the parietal cortex ( $n=6-8$, in each group) and remained at this low level throughout the 90-min vascular occlusion. During ischemia, no significant difference in residual CBF was observed in any group except sham group. When the intraluminal thread was removed after the 90-min ischemia, CBF instantaneously rose and returned to the baseline 10 minutes after reperfusion in all groups except the sham group.

Pioglitazone showed strong neuroprotective effect under MCAO in vivo and OGD in vitro

The infarction volume in MCAO rats was measured using TTC staining. As shown in Fig. 1A, normal tissues were stained in red, while infarction area was stained in white. No infarction area was identified in sham group, while MCAO group and vehicle group had significantly higher rate of infarction compared to the
Table 1. Physiological parameters for rats before, during and after middle cerebral artery occlusion. MABP: mean arterial blood pressure, HR: heart rate. Rats received repeated intraperitoneal administration of pioglitazone $(10 \mathrm{mg} / \mathrm{kg})$ daily for three days. All variables were measured prior to occlusion, $90 \mathrm{~min}$ after occlusion, and $90 \mathrm{~min}$ after reperfusion, and were presented as mean \pm SD and were analyzed using multivariate analysis of variance.S: sham group; M: MCAO group; P: pioglitazone group; V: vehicle group

\begin{tabular}{|c|c|c|c|c|}
\hline & S & $P$ & $\mathrm{~V}$ & M \\
\hline \multicolumn{5}{|l|}{ before occlusion } \\
\hline $\mathrm{pH}[\mathrm{U}]$ & $7.45 \pm 0.03$ & $7.43 \pm 0.02$ & $7.37 \pm 0.04$ & $7.40 \pm 0.03$ \\
\hline $\mathrm{PCO}_{2}[\mathrm{mmHg}]$ & $40.6 \pm 4.4$ & $42.1 \pm 4.2$ & $39.8 \pm 2.5$ & $41.5 \pm 4.1$ \\
\hline $\mathrm{PO}_{2}[\mathrm{mmHg}]$ & $201.5 \pm 37.1$ & $189.5 \pm 41.4$ & $195.6 \pm 27.8$ & $207.5 \pm 34.5$ \\
\hline $\mathrm{HR}[\mathrm{bpm}]$ & $254 \pm 15$ & $261 \pm 17$ & $248 \pm 12$ & $263 \pm 17$ \\
\hline MABP [mmHg] & $108.4 \pm 6.5$ & $114.4 \pm 5.8$ & $112.8 \pm 5.8$ & $116.1 \pm 4.7$ \\
\hline Glucose & $6.41 \pm 0.27$ & $6.44 \pm 0.38$ & $6.37 \pm 0.65$ & $6.50 \pm 0.82$ \\
\hline \multicolumn{5}{|c|}{90 min after occlusion } \\
\hline $\mathrm{pH}[\mathrm{U}]$ & $7.39 \pm 0.02$ & $7.41 \pm 0.03$ & $7.37 \pm 0.02$ & $7.43 \pm 0.04$ \\
\hline $\mathrm{PCO}_{2}[\mathrm{mmHg}]$ & $40.3 \pm 4.7$ & $42.8 \pm 5.2$ & $39.1 \pm 2.5$ & $41.5 \pm 3.4$ \\
\hline $\mathrm{PO}_{2}[\mathrm{mmHg}]$ & $193.5 \pm 25.4$ & $202.5 \pm 35.1$ & $202.2 \pm 38.2$ & $195.5 \pm 25$. \\
\hline $\mathrm{HR}[\mathrm{bpm}]$ & $252 \pm 12$ & $260 \pm 12$ & $258 \pm 15$ & $248 \pm 17$ \\
\hline MABP $[\mathrm{mmHg}]$ & $114.5 \pm 5.5$ & $112.5 \pm 3.7$ & $112.6 \pm 4.2$ & $118.8 \pm 6.5$ \\
\hline Glucose & $6.45 \pm 0.47$ & $6.42 \pm 0.61$ & $6.46 \pm 0.52$ & $6.58 \pm 0.85$ \\
\hline \multicolumn{5}{|c|}{90 min after reperfusion } \\
\hline $\mathrm{pH}[\mathrm{U}]$ & $7.39 \pm 0.02$ & $7.45 \pm 0.02$ & $7.43 \pm 0.02$ & $7.42 \pm 0.02$ \\
\hline $\mathrm{PCO}_{2}[\mathrm{mmHg}]$ & $40.7 \pm 2.5$ & $43.5 \pm 3.2$ & $44.2 \pm 1.3$ & $40.1 \pm 3.2$ \\
\hline $\mathrm{PO}_{2}[\mathrm{mmHg}]$ & $212.5 \pm 9.6$ & $190.5 \pm 8.4$ & $197.1 \pm 8.3$ & $192.2 \pm 34 . \mathrm{s}$ \\
\hline $\mathrm{HR}[\mathrm{bpm}]$ & $250 \pm 9$ & $245 \pm 7$ & $251 \pm 9$ & $248 \pm 16$ \\
\hline MABP [mmHg] & $107.8 \pm 8$ & $103.5 \pm 7.2$ & $114.6 \pm 8.3$ & $117.2 \pm 6.0$ \\
\hline Glucose & $6.41 \pm 0.53$ & $6.46 \pm 0.72$ & $6.51 \pm 0.81$ & $6.35 \pm 0.68$ \\
\hline
\end{tabular}




\section{Cellular Physiology Cell Physiol Biochem 2018;45:2351-2368 \begin{tabular}{l|l|l} 
DOI: 10.1159/000488183 & Ond Biochemistry 2018 The Author(s). Published by S. Karger AG, Basel \\
Published onmw.karger.com/cpb
\end{tabular} \\ Xia et al.: Pioglitazone Protected Against Pyroptosis by Activating PPAR- $\gamma$}

Fig. 1. Pioglitazone confers a robust neuroprotection against MCAO and OGDinduced ischemia injury. (A) Brain infarct volume was determined by TTC staining 3d after MCAO. (B) Bar chart indicating the change in neurological scores between sham, MCAO, pioglitazone and vehicle groups. (C) Histopathological changes on day 3 post-reperfusion with or without pioglitazone treatment in rats. Scale bar, $100 \mu \mathrm{m}$. (D) Photomicrographs of the cortex penumbra of rat brains used for the TUNEL assay. Scale bar, $100 \mu \mathrm{m}$. (E) Quantification of apoptotic cells by the TUNEL assay. Data are expressed as mean \pm S.D. $n=6-8$ rats for each group. $\#$, $\mathrm{P}<0.05$ vs. the sham group; ${ }^{*} \mathrm{P}<0.05$ vs. the MCAO group. S: sham group; P: pioglitazone group; V: vehicle group; M: MCAO group; (F) The survival of astrocytes exposed to OGD for different periods of time. Survival was determined $24 \mathrm{~h}$ after OGD injury by the CCK-8 kit according to the manufacturer's protocol $(n=3$ experiments, $\#, \mathrm{P}<0.05$ and ${ }^{\# \#,} \mathrm{P}<0.001$ vs. control). (G) The astrocytes exposed to OGD for $2 \mathrm{~h}$ were incubated with pioglitazone at concentrations ranging from 0 to 50 $\mu \mathrm{M}$. ( $\mathrm{n}=3$ experiments, ${ }^{\#,} \mathrm{P}<0.05$ and \#\#, $\mathrm{P}<0.01$ vs. OGD group).

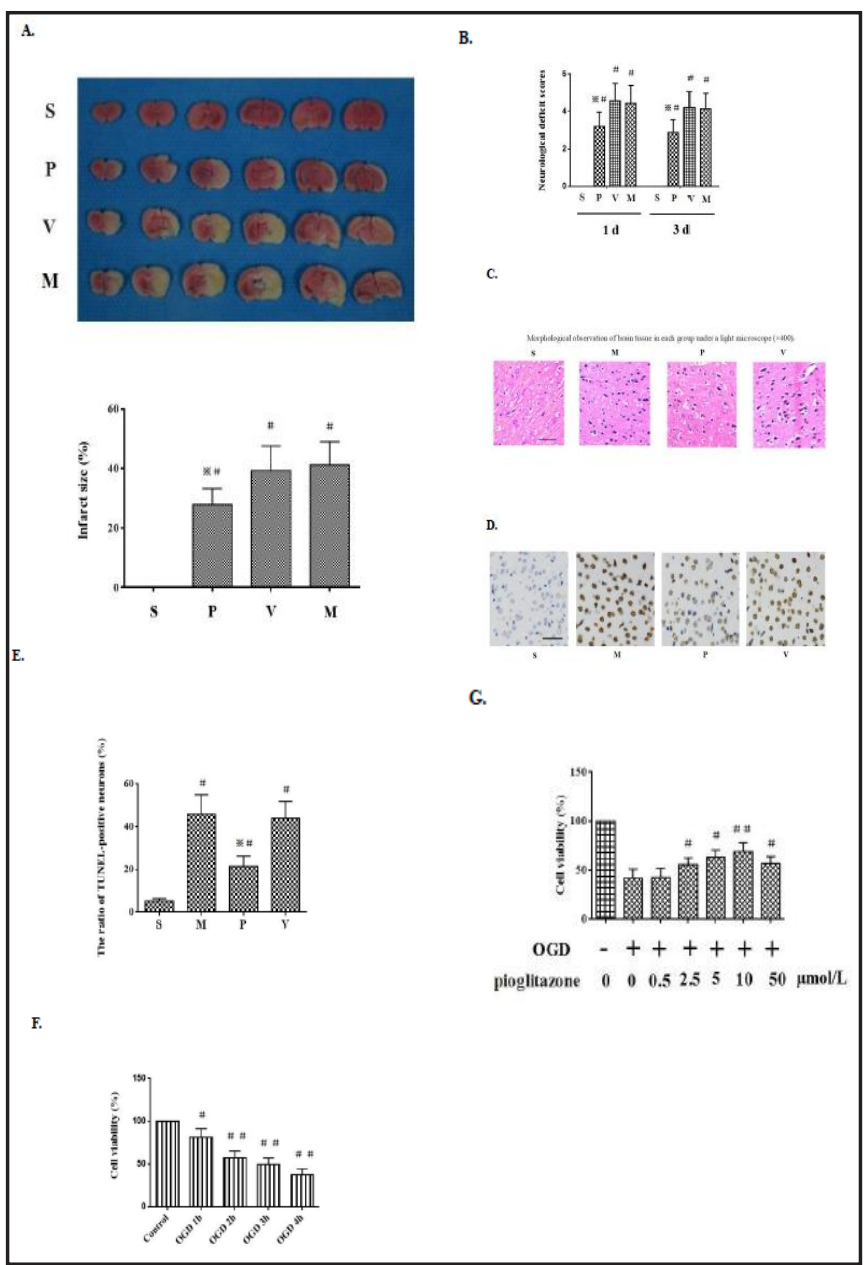

sham group $(\mathrm{P}<0.05)$. In addition, pioglitazone significantly decreased the infarction area in the experiment group $(\mathrm{P}<0.05)$.

Our research showed that pioglitazone improved neurological performance post-MCAO, as measured with the NSS. Rats in MCAO group had the highest neurological deficit score, whereas the neurological deficit scores of rats treated with pioglitazone were significantly lower 3 days after reperfusion (Fig. 1B).

Fig. 1C showed the effect of pioglitazone preconditioning on the morphological change in ischemic rats. Using HE staining method, morphological changes in ischemic cortex were detected in the ischemic MCAO group: neuronal cell loss, nuclei shrinkage and dark staining of neurons were observed. Repeated administration of pioglitazone reduced such pathological changes significantly.

There is no apparent positively stained cells in the penumbra region of the sham group, while a large number of positive apoptotic cells with positive stained nucleus were observed in the MCAO and vehicle group, and shrinkage of nucleus or chromatin margination was observed. The proportion of TUNEL positive neurons in ischemic penumbra of MCAO group was $45.8 \%$ compared to only $21.3 \%$ for pioglitazone group (Fig. $1 \mathrm{D}$ and $\mathrm{E}, \mathrm{P}<0.05$ ).

Furthermore, we investigated whether administration of pioglitazone could relieve OGD-caused hypoxia injury in vitro. OGD-caused neuronal death was time-dependent, as shown by a significant reduce in cell survival rate with longer time ( $82.3 \%$ for $1 \mathrm{~h}, 48.9 \%$ for $2 \mathrm{~h}, 43.8 \%$ for $3 \mathrm{~h}$ and $31.5 \%$ for $4 \mathrm{~h}$, respectively) (Fig. $1 \mathrm{~F}$ ). In fact, the protective action of pioglitazone was detected on primary astrocytes $24 \mathrm{~h}$ after OGD insult. The data showed that pioglitazone remarkably increased the cell viability of OGD-treated neurons in a 
Fig. 2. Pioglitazone significantly inhibited pyroptosis in vivo and in vitro models by activating PPAR- $\gamma$. (A) Western blot images and quantitative analysis of PPAR- $\gamma$ expression in vivo $(\mathrm{n}=6-8$, rats for each group. ${ }^{\#} \mathrm{P}<0.05$ vs. the sham group; $*$ $\mathrm{P}<0.05$ vs. the MCAO group). (B) Western blot images and quantitative analysis of PPAR- $\gamma$ expression in vitro $(n=3$ experiments, ${ }^{\#,} \mathrm{P}<0.05$ vs. the control group; $*$ $\mathrm{P}<0.05$ vs. the OGD group). (C) Western blot analysis of the expressions of caspase-1, NLRP3 and ASC in vivo $(\mathrm{n}=6-8$, rats for each group. $\#, P<0.05$ vs. the sham group; ${ }^{\mathrm{P}}<0.05$ vs. the MCAO group). (D) ELISA of levels of IL-1 $\beta$ and IL-18 in penumbra region. (E) Western blot analysis of the expression of caspase-1, NLRP3 and ASC in vitro. (F) Quantitative analysis for the level of caspase-1, NLRP3 and ASC in vitro. (G) ELISA of levels of IL-1 $\beta$ and IL18 , as well as LDH release in primary culture cortical astrocytes exposed to OGD with or without $10 \mu \mathrm{M}$ pioglitazone $(\mathrm{n}=$ 3 , experiments, ${ }^{\#} \mathrm{P}<0.05$ vs. the control group; ${ }^{\mathrm{P}}<0.05$ vs. the OGD group), Data are expressed as mean \pm S.D.
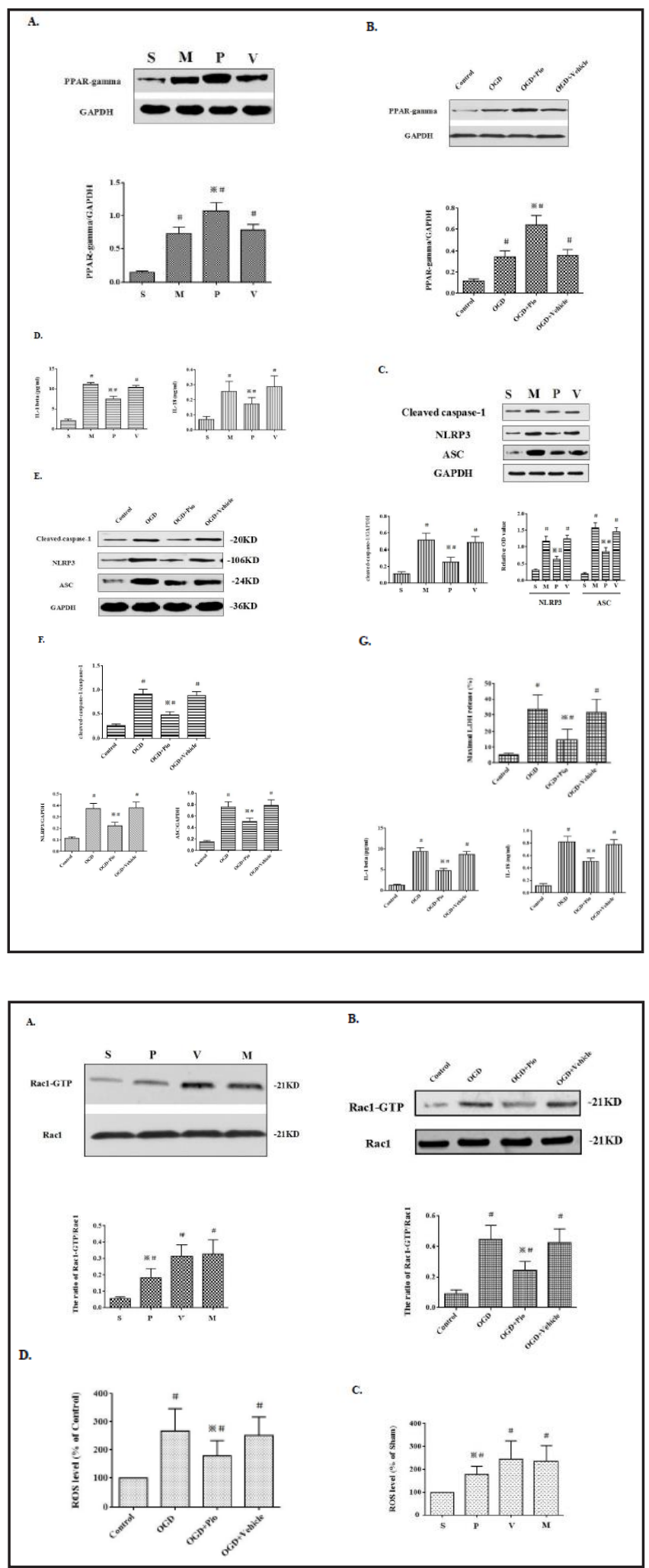

Fig. 3. Pioglitazone notably reduced Rac1 activity and ROS production in vivo and in vitro models. (A, B) Western blot analysis of the expression of Rac1-GTP following cerebral ischemia model in vivo and in vitro. (C, D) pioglitazone significantly alleviated ROS generation in vivo and in vitro models. Data are expressed as mean \pm S.D. $\mathrm{n}=6-8$, rats for each group. ${ }^{\#} \mathrm{P}<0.05$ vs. the sham group; $※, P<0.05$ vs. the for MCAO group. $\mathrm{n}=3$, experiments, \#, $\mathrm{P}<0.05$ vs. the sham or the control groups; ${ }^{*} \mathrm{P}<0.05$ vs. the MCAO or OGD groups.

dose-dependent manner with the concentration of $10 \mu \mathrm{M}$ having the best effect (Fig. 1G).

Pioglitazone induces PPAR- $\gamma$ expression and alleviate ischemia/hypoxia-induced pyroptosis

In order to further explore whether PPAR- $\gamma$ is involved in the pioglitazone-induced neuroprotection against cerebral ischemia injury, the protein level of PPAR- $\gamma$ was measured. 
Fig. 4. Pioglitazone alleviated cytoplasmic translocation of HMGB-1 and RAGE expression in both MCAO and OGD models. (A). Western blot images and quantitative analysis of cytoplasmic translocation of HMGB-1 in MCAO model. (B). The plasma HMGB1 level in different groups. (C). Western blot images and quantitative analysis of RAGE expression in MCAO model. $n=6-8$, rats for each group. ${ }^{\# ~} \mathrm{P}<0.05$ vs. the sham group; $※, \mathrm{P}<0.05$ vs. the MCAO group. (D, E) Western blot images and quantitative analysis of cytoplasmic translocation of HMGB-1 and RAGE expression in OGD model. $\mathrm{n}=3$, experiments, ${ }^{\#,} \mathrm{P}<0.05$ vs. the control group; ${ }^{*} \mathrm{P}<0.05$ vs. the OGD group. Data are expressed as mean \pm S.D.

PPAR- $\gamma$ protein expression also increased $3 \mathrm{~d}$ after reperfusion in rats pretreated with pioglitazone $(\mathrm{P}<0.05$, Fig. 2A)

The expression of PPAR- $\gamma$ protein in cultured primary astrocytes was measured $24 \mathrm{~h}$ after OGD by western blot. As depicted in Fig. 2B, the expression of PPAR- $\gamma$ protein in cultured astrocytes significantly increased $24 \mathrm{~h}$ after $\mathrm{OGD}(\mathrm{P}<0.05$ vs. control group). Pioglitazone could further

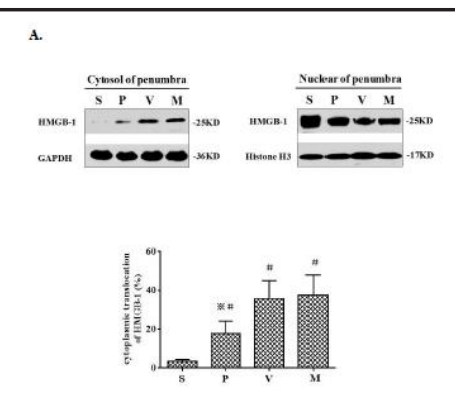

D.

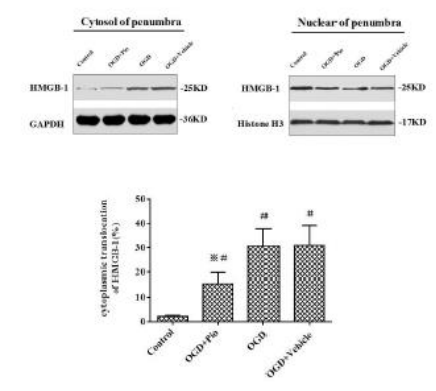

B.

c.
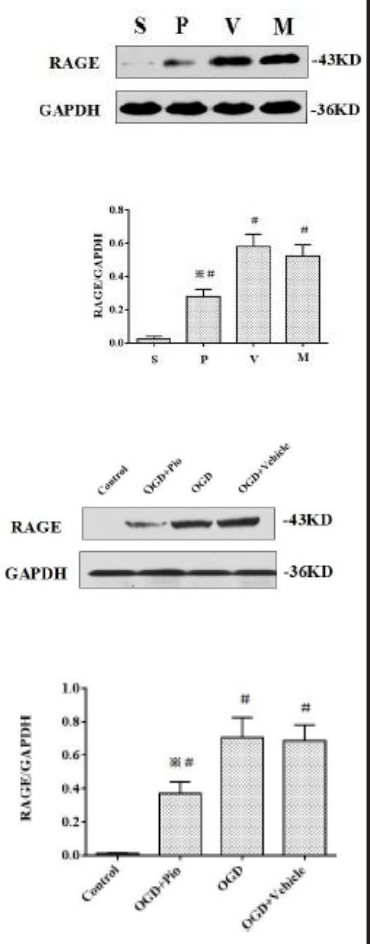
increase the expression of PPAR- $\gamma$ protein in cultured astrocytes $24 \mathrm{~h}$ after OGD exposure ( $\mathrm{P}<0.05$ vs. OGD group). These results indicated that the protective effects of pioglitazone may be associated with the increase of PPAR- $\gamma$ expression in MCAO rats and OGD-exposed astrocytes.

In order to understand the distinct role of pioglitazone in the regulation of cell death, we analyzed the regulation of pioglitazone on pyroptosis. Our research showed that pioglitazone could protect cells against the ischemia-induced pyroptosis, as demonstrated by the decrease of caspase-1, NLRP3 and ASC, as well as IL-1 $\beta$ and IL-18 (Fig. 2C and D). In addition, pioglitazone also reduced OGD-induced caspase-1, NLRP3 and ASC expressions as well as IL-1 $\beta$ and IL-18 secretion and LDH release, suggesting a slowdown on pyroptosis (Fig. 2E-G).

Pioglitazone inhibits Rac1 activity and ROS production in both in vivo and in vitro models

The active form of Rac1 is Rac1-GTP. The level of Rac1-GTP was measured by pulldown assays. As shown in Fig. 3A and B, Rac1-GTP expression increased in MCAO rats, but pioglitazone could remarkably reduce the Rac1-GTP level. Similarly, Rac1-GTP was also elevated in cultured primary astrocytes after OGD insult and pioglitazone also could suppress the Rac1 activity.

ROS production was previously reported to be one of the mechanisms involved in pyroptosis. In this study, the intracellular ROS level was quantified using dichlorofluorescein diacetate (DCFH-DA). As illustrated in Fig.3C and D, ischemia reperfusion injury significantly 


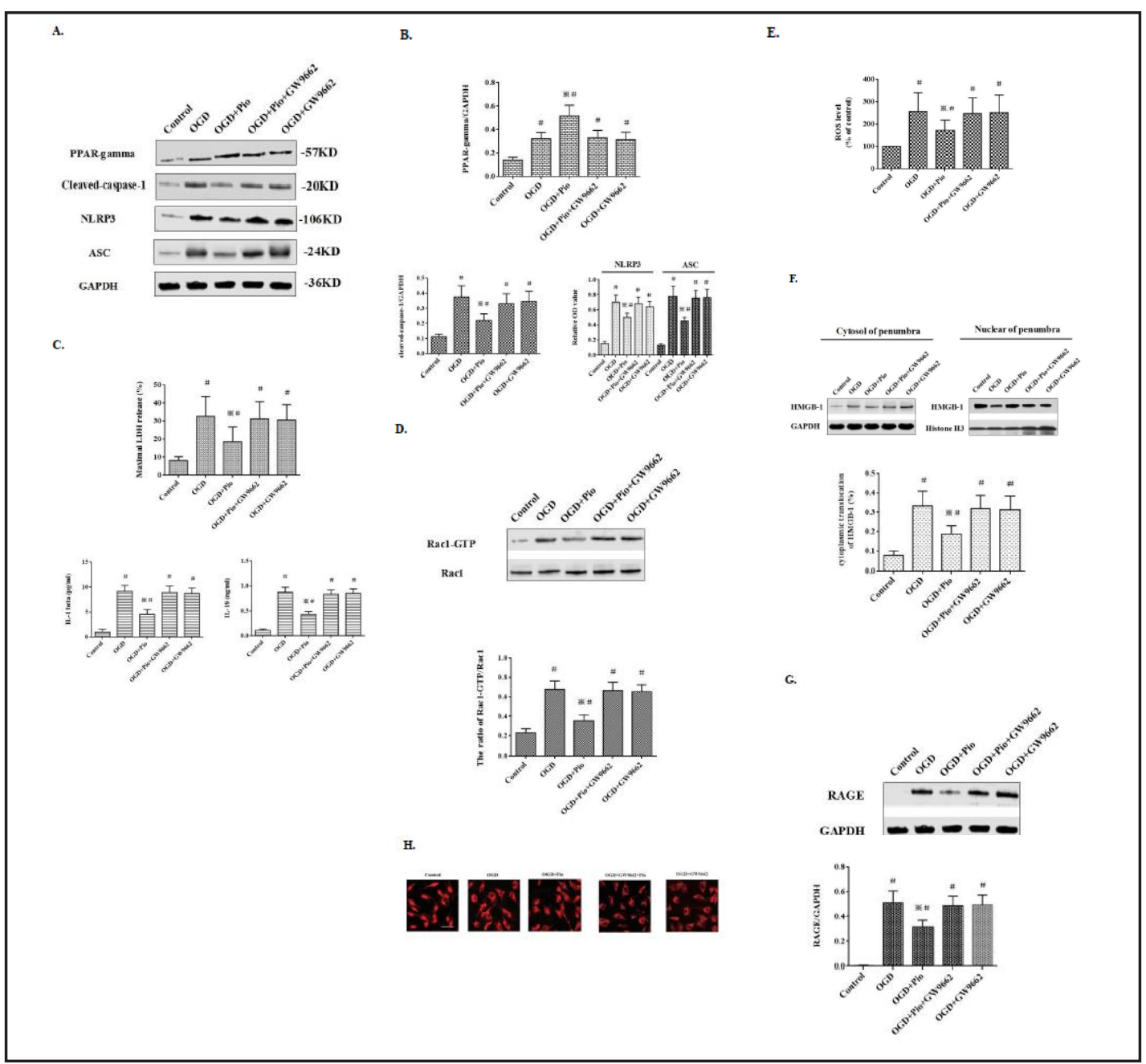

Fig. 5. PPAR- $\gamma$ irreversible antagonist GW9662 abolishes the neuroprotection of pioglitazone in OGD model. (A, B). Expressions of PPAR- $\gamma$, caspase-1, NLRP3 and ASC in astrocytes treated with pioglitazone and the PPAR- $\gamma$ inhibitor GW9662 in vitro model. (C). The levels of IL-1 $\beta$ and IL-18 as well as LDH release in astrocytes treated with pioglitazone $(10 \mu \mathrm{M})$ and the PPAR- $\gamma$ inhibitor GW9662 $(10 \mu \mathrm{M})$ in OGD model. (D, E) Rac1 activity and the intracellular ROS level of astrocytes treated with pioglitazone $(10 \mu \mathrm{M})$ and the

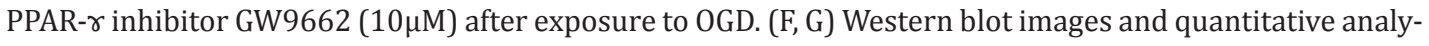
sis of cytoplasmic translocation of HMGB-1 and RAGE expression in astrocytes treated with pioglitazone $(10 \mu \mathrm{M})$ and the PPAR- $\gamma$ inhibitor GW9662 $(10 \mu \mathrm{M})$ in OGD model. $(\mathrm{H})$ PPAR- $\gamma$ inhibitor GW9662 $(10 \mu \mathrm{M})$ abolished the effect of pioglitazone $(10 \mu \mathrm{M})$ on the cytoplasmic translocation of HGMB-1, determined by immunofluorescent staining. Scale bar, $50 \mu \mathrm{m}$. $\mathrm{n}=3$, experiments, ${ }^{\#} \mathrm{P}<0.05$ vs. the control group; ${ }^{*} \mathrm{P}<0.05$ vs. the OGD group. Data are expressed as mean \pm S.D.

increased ROS production in the cerebral penumbra cortex in both MCAO and vehicle groups, (compared to the sham group). DCF production level declined significantly in the cerebral penumbra cortex of the pioglitazone group, compared to the MCAO and vehicle groups $(\mathrm{P}<0.05)$. Moreover, quantitative analysis showed that the rate of ROS accumulation in the OGD group increased to $267.3 \%$ compared to the control group. On the other hand, administration of pioglitazone inhibited the ROS level by $178.4 \% 24 \mathrm{~h}$ after OGD, compared to the OGD group. 


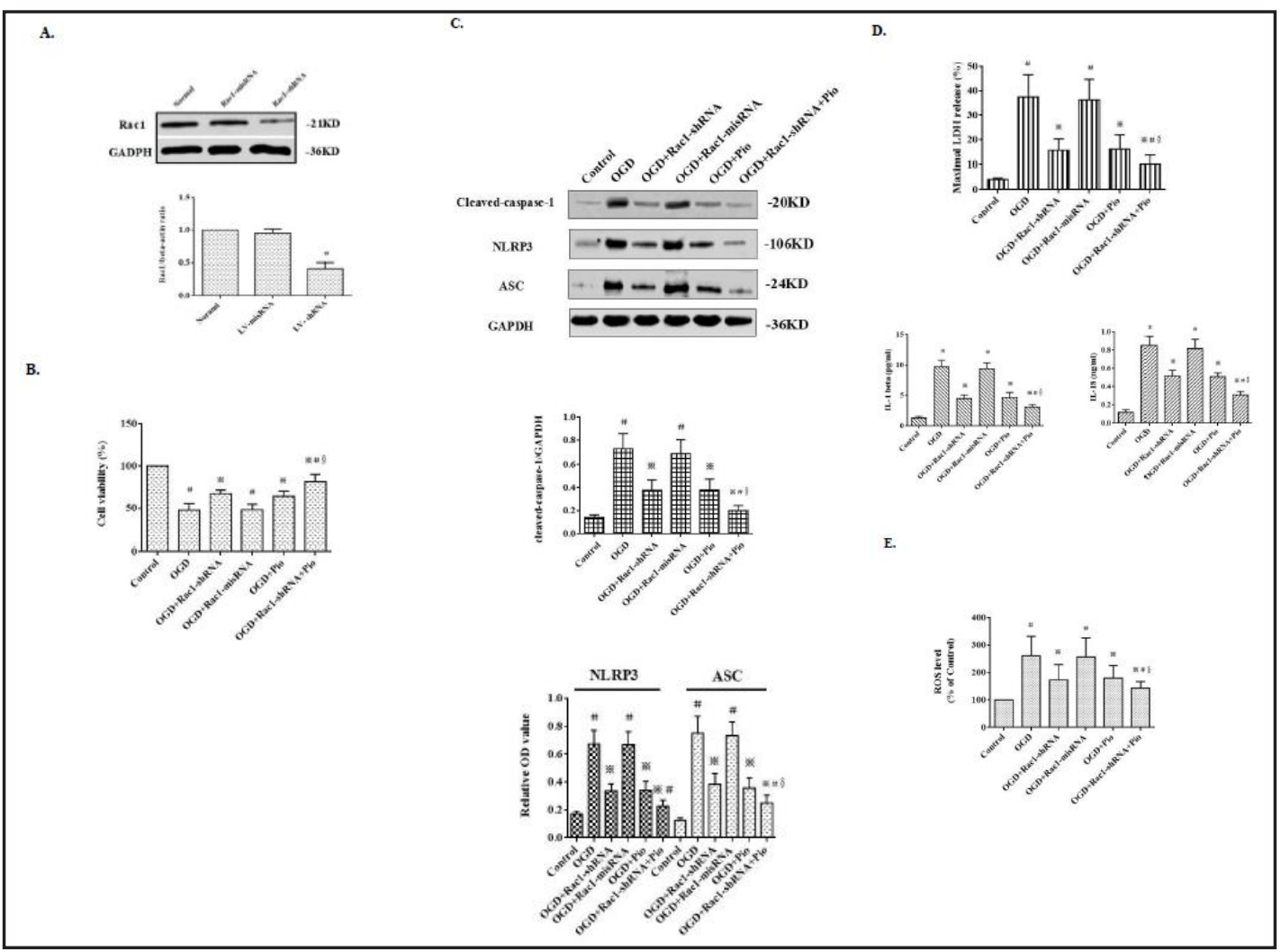

Fig. 6. Rac1 knockdown facilitated the inhibitory effect of pioglitazone on OGD-induced pyroptosis in primary culture neurons. (A) Cell lysate taken from primary culture astrocytes was used to determine the protein levels of Rac1 with Western blot analysis. Decreased expression of Rac1 was observed in cells infected with Rac1shRNA when compared to control cells and Rac1 misRNA infected cells. (B). Rac1 knockdown and pioglitazone improved the survival of astrocytes exposed to OGD. (C) Western blot images and quantitative analysis of pyroptosis-related proteins: caspase-1, NLRP3 and ASC. (D) The inhibitory actions of Rac1 knockdown and $10 \mu \mathrm{m}$ pioglitazone on the levels of IL-1 $\beta$ and IL-18 as well as LDH release in astrocytes exposed to OGD. (E) The inhibitory actions of Rac1 knockdown and $10 \mu \mathrm{m}$ pioglitazone on the level of intracellular ROS. $\mathrm{n}=3$, experiments, ${ }^{\#,} \mathrm{P}<0.05$ vs. the control group; ${ }^{*} \mathrm{P}<0.05$ vs. the OGD group. ${ }^{\S} \mathrm{P}<0.05$ vs. the OGD+Pio or OGD+Rac1-shRNA group. Data are expressed as mean \pm S.D.

Pioglitazone inhibits the ischemia-induced cytoplasmic translocation of HMGB-1 and the expression of RAGE

To explore whether pioglitazone inhibits HMGB-1, western blotting was used to measure the cytoplasmic translocation of HMGB-1 and its target RAGE in the ischemic cortex $3 \mathrm{~d}$ after MCAO. The ratio of cytoplasmic translocation was expressed as cytoplasmic fraction/ (cytoplasmic fraction + nuclear fraction) of HMGB-1. Our findings demonstrated that the cytoplasmic translocation of HMGB-1 increased meaningfully in the ischemia cortical penumbra in rats of both MCAO and vehicle groups. Nevertheless, the ischemia-induced cytoplasmic translocation of HMGB-1 was blocked by repeated application of pioglitazone (Fig. 4A, $\mathrm{P}<0.05$ ). Moreover, we detected the effect of pioglitazone on HMGB-1 in the plasma and found that the mean plasma level of HMGB-1 was significantly increased in the MCAO and vehicle-treated groups compared with the sham-treated group $(\mathrm{P}<0.05)$. However, the results of ELISA showed that pioglitazone could reverse the increase of HMGB-1 in the plasma (Fig. 4B, $\mathrm{P}<0.05$ ).

To further confirm the inhibition of pioglitazone on HMGB-1 activation, we measured the RAGE protein expression in the ischemic cortex. The results showed that RAGE was low in in the sham group. In the MCAO group, RAGE significantly increased $3 \mathrm{~d}$ after ischemia. 


\section{Cellular Physiology Cell Physiol Biochem 2018;45:2351-2368

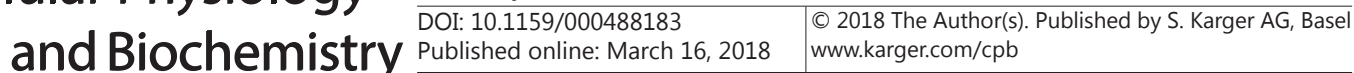 \\ Xia et al.: Pioglitazone Protected Against Pyroptosis by Activating PPAR- $\gamma$}

Similarly, pioglitazone also significantly inhibited the RAGE expression in the penumbral cortex $3 \mathrm{~d}$ after ischemia insult (Fig. $4 \mathrm{C}, \mathrm{P}<0.05$ ).

Western blot analysis also showed that cytoplasmic translocation of HMGB-1 and increased RAGE expression presented in the OGD-treated astrocytes. In cultured primary astrocytes exposed to OGD for $2 \mathrm{~h}$, pioglitazone effectually inhibited the increase of cytoplasmic translocation of HMGB-1 and RAGE expression, suggesting that pioglitazone had a direct protective effect on astrocytes and could block the activation of HMGB-1/RAGE signals in astrocytes (Fig. 4D and E, $\mathrm{P}<0.05$ ).

PPAR- $\gamma$ irreversible antagonist GW9662 inhibits the neuroprotection of pioglitazone in vitro model

In order to investigate whether PPAR- $\gamma$ mechanism is required for pioglitazone-induced neuroprotection against hypoxia insult in OGD model, we used PPAR- $\gamma$ specific antagonist GW9662 to block PPAR- $\gamma$-mediated signaling. As shown in Fig. 5A-E, GW9662 inhibited the PPAR- $\gamma$ expression induced by pioglitazone. In addition, the expressions of pyroptosisrelated proteins, IL-1 $\beta$, and IL-18, LDH release, the inhibition of Rac1 activity, and ROS production were all completely deteriorated in the cells co-treated with GW9662 $(\mathrm{P}<0.05)$.

In addition, the effect of pioglitazone on cytoplasmic translocation of the HMGB1 and RAGE expression were abrogated in the cells co-treated with GW9662 (Fig. 5F and G). We further confirmed that OGD triggered cytoplasmic translocation of the HMGB-1 by immunofluorescent staining. We found HMGB-1 predominantly located in the nucleus in normal primary cultured astrocytes of control group, whereas HMGB-1 was almost entirely distributed in the cytoplasm $24 \mathrm{~h}$ after OGD in cells of OGD alone group. Pioglitazone significantly inhibited cytoplasmic translocation of the HMGB-1. However, GW9662 abolished this effect of pioglitazone (Fig. 5H).

Therefore, these data suggested that the inhibitory effects of pioglitazone on pyroptosis and HMGB-1/RAGE signal pathway, as well as the reductions of Rac1 activity and ROS production, were mediated through PPAR- $\gamma$ activation mechanism.

\section{Deficiency of Rac1 promoted the neuroprotection function of pioglitazone}

Firstly, we determined Rac1 protein expression after virus infection-induced Rac1 knockdown in the primary cultured cortical astrocytes using western blot analysis. As shown in Fig. 6A, there was a significant decrease in Rac1 protein expression in the primary cultured cortical astrocytes infected with Rac1-shRNA in comparison to cells infected with misRNA and uninfected cells.

The cultured primary astrocytes were treated with lentivirus containing Rac1 small hair RNA (Rac1-shRNA) alone or with pioglitazone in OGD-induced ischemia model. Cell viability, the levels of pyroptosis related proteins, IL-1 $\beta$, and IL-18, and LDH release were analyzed. Rac1 inhibition improved cell viability, reduced Rac1 activity and ROS generation, suppressed expressions of pyroptosis related proteins including NLRP3, ASC and caspase-1 level, and alleviated IL-1 $\beta$, IL-18 and LDH release. Such results confirmed that the inhibition of Rac1 could confer neuroprotective effects involving in the suppression of pyroptosis (Fig. 6B-E). Furthermore, similar results were obtained from the pioglitazone-treated group. OGD-triggered pyroptosis further decreased in the group co-treated with Rac1-shRNA and pioglitazone, suggesting that the deficiency of Rac1 promoted this neuroprotective function of pioglitazone.

\section{Discussion}

Perioperative ischemic stroke is a major cause of long-term disability and cognitive dysfunction and currently attracts more and more attention due to the high mortality and disability associated with this. Health providers, including anesthesiologists, are actively seeking effective protective strategies. During the perioperative period, central nervous 
system is extremely sensitive to any drop in blood flow and impairment of substrate delivery [35]. Compelling evidence from animal models demonstrated that inflammatory responses were activated after cerebral ischemia and acted as crucial mediators in the pathogenesis of stroke-induced injuries [3, 4, 36, 37].

Pyroptosis, a unique pro-inflammatory programmed cell death, is initiated by inflammatory caspases [7, 38]. When organs suffer from ischemic insult, injured tissues release danger signals that lead to the assembly of NOD-like receptor protein 3 (NLRP3) inflammasomes and their activation. NLRP3 inflammasome, an intracellular heteromeric complex, contains NLRP3 protein and apoptosis-associated speck-like protein containing caspase recruitment domain (ASC) and pro-caspase-1. Following NLRP3 inflammasome activation, pro-caspase- 1 is cleaved via autocatalytic processes to yield the active form of caspase- $1[38,39]$. The active caspase- 1 subsequently leads to the release of the proinflammatory cytokines IL-1 $\beta$ and IL-18 and initiates the inflammatory cascade [40]. IL$1 \beta$ is a potent endogenous pyrogen that stimulates expressions of diverse cytokines and chemokines [41]. IL-18 induces interferon (IFN)- $\gamma$ production and is important for the activation of cells of innate immunity [42]. Both IL-1 $\beta$ and IL-18 are involved in caspase1 -dependent pore formation or cytokine secretion during pyroptosis. Therefore, caspase-1 dependence is a definitive feature of pyroptosis that is characterized by the release of proinflammatory contents and plasma membrane rupture. Recent studies have demonstrated that pyroptosis mediated the death of renal and cardiac cells, leading to kidney and heart failure $[11,12,43]$. Our findings were consistent with those previously reported results. The expressions of NLRP3 inflammasome-associated proteins: NLRP3, ASC, and caspase-1, were examined in this study to assess inflammasome activity. Our findings indicated that increased expressions of inflammasome-associated proteins and cytokines such as IL- $1 \beta$ and IL-18 in cerebral penumbra region were associated with structural and functional changes in those cerebral tissues. Our in vitro model further demonstrated that oxygen-glucose deprivation (OGD) increased the expressions of pyropotosis-relative proteins in cultured primary astrocytes, which was accompanied by decreased cell viability and elevated lactate dehydrogenase (LDH) release. Hence, our findings revealed a new signaling mechanism involved in pyroptotic neuronal cell death under ischemia/reperfusion injuries.

Given the importance of pyroptosis in the pathophysiological of cerebral ischemia, it is essential to understand its mechanism. PPARs (peroxisome-proliferator-activated receptors) are ligand-activated transcription factors belonging to the nuclear receptor superfamily. Three PPAR isoforms have been identified: PPAR- $\gamma$; PPAR- $\alpha$ and PPAR- $\beta$. Cerebral ischemic injury enhanced the expression of PPAR- $\gamma$ mRNA and protein in neurons, which maximal levels are observed after $24 \mathrm{~h}$, and increased PPAR- $\gamma$ protein can still be detected up to $14 \mathrm{~d}$ after ischemic injury [44]. However, increased PPAR- $\gamma$ expression might not be functionally important because cerebral ischemia reduces the DNA binding of PPAR- $\gamma$. Importantly, DNA binding is fully restored by application of the PPAR- $\gamma$ agonist. Substantial studies have demonstrated that PPAR- $\gamma$ agonists, such pioglitazone, efficiently protect against cerebral ischemia in rodents [15-18]. As shown recently, the expression of PPAR- $\gamma$ in the brain has been revealed a powerful anti-inflammatory potential against ischemic insult. Activation of PPAR- $\gamma$ by pioglitazone attenuates the expression of tumor necrosis factor $\alpha$ (TNF- $\alpha$ ), intercellular adhesion molecule (ICAM-1) and down-regulates the production of IL-1 $\beta$ or the induction of cyclooxygenase 2 (COX-2) and inducible nitric oxide synthase (iNOS) [17, 18]. Moreover, pioglitazone inhibit NF-kB signaling and p38 stress kinase $[15,16]$. Because pyroptosis is an inflammatory response, it is important to understand whether pioglitazone could effectively inhibit pyroptosis in vivo and in vitro. In this study, repeated application of pioglitazone, a PPAR- $\gamma$ agonist, reduced the infarct volume and notably improved the neurological deficits in vivo. Moreover, we reported for the first time that pioglitazone could effectively antagonize the neuronal pyroptosis caused by ischemia and hypoxia by inhibiting pyroptosis-related proteins such as caspase-1, NLRP3 and ASC and by reducing the release of cytokines, like IL-1 $\beta$ and IL-18, in vivo. Furthermore, we investigated whether PPAR- $\gamma$ mechanism was necessary for pioglitazone-induced protection against cerebral ischemia 
using the PPAR- $\gamma$ specific antagonist GW9662 to block PPAR- $\gamma$-mediated signaling. Our findings demonstrated that pioglitazone increased the cell viability of OGD-treated astrocytes in a dose-dependent manner, lowered the elevated expressions of OGD-induced NLRP3, ASC and caspase-1, and inhibited the LDH release. The combination of GW9662 and pioglitazone significantly attenuated anti-pyroptosis actions of pioglitazone. These data suggested that PPAR- $\gamma$ irreversible antagonist GW9662 could abolish pioglitazone's anti-pyroptosis actions against OGD, indicating that pioglitazone-induced anti-pyroptosis effect is mediated by its binding to PPAR- $\gamma$.

Importantly, to further understand the function of pioglitazone in cerebral ischemiatriggered pyroptosis, we explored the downstream signaling mechanisms and demonstrated that pioglitazone significantly decreased the level of Rac1-GTP, the active form of Rasrelated C3 botulinum toxin substrate 1 (Rac1), in both MCAO and OGD models. Moreover, Rac1 knockdown by using lentivirus could block the OGD-induced pyroptosis of cultured primary astrocytes with the reduction of NLRP3/ASC and caspase-1 expressions. OGDinduced IL-1 $\beta$ and IL-18 secretion as well as LDH release were also inhibited by the Rac1 knockdown. Interestingly, OGD-triggered pyroptosis further decreased in the Rac1-shRNA and pioglitazone co-treated group. Growing evidence has shown that Rac1 contributes to the induction of oxidative stress in neurons by facilitating the activation of NADPH oxidase [21], a key membrane enzyme that generates reactive oxygen species (ROS). Hence, we believe that ROS reduction may be involved in the neuroprotective mechanism of pioglitazonemediated inhibition of pyroptosis. We further validated that ROS plays a key regulatory role in pioglitazone-mediated inhibition of pyroptosis and discovered that pioglitazone alleviates the generation of ROS in both in vivo and in vitro models. Furthermore, Rac1 knockdown also accelerates the decline of OGD-induced ROS production. Pioglitazone alleviated OGD-induced

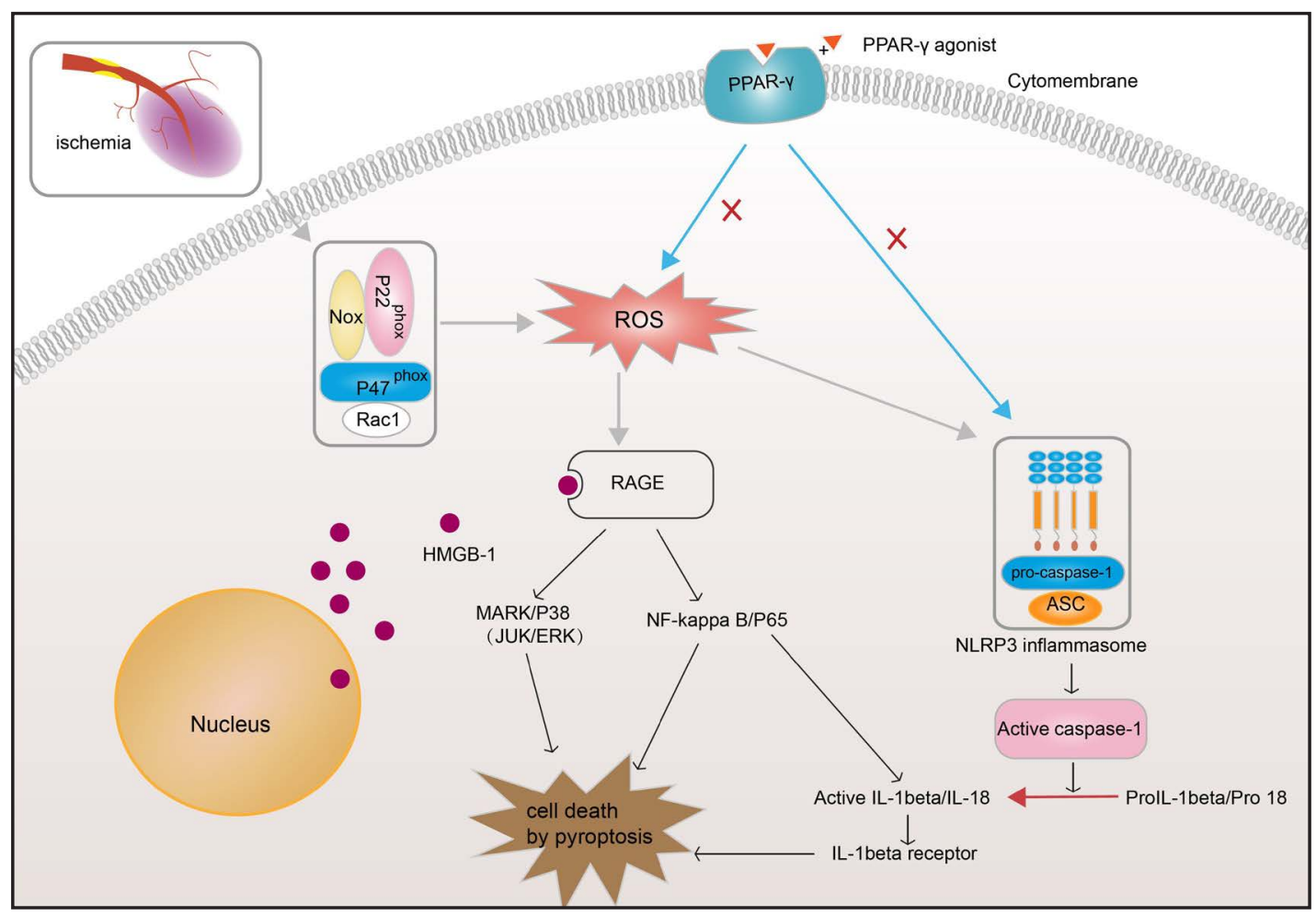

Fig. 7. Schematic representation of the proposed anti-pyroptotic signalling pathways triggered by pioglitazone in ischaemic neurons. Pioglitazone activates PPAR- $\gamma$ and reduces excessive ROS by inhibiting Rac1 activation. The reduced level of ROS in turn decreases the activation of NLRP3 inflammasome and HMBG1RAGE pathway, which ultimately inhibits the pyroptotic signaling pathways to block pyroptosis.

\section{KARGER}




\section{Cellular Physiology Cell Physiol Biochem 2018;45:2351-2368

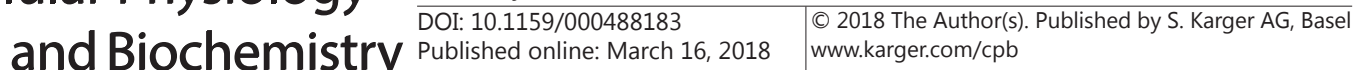

Xia et al.: Pioglitazone Protected Against Pyroptosis by Activating PPAR- $\gamma$

pyroptosis through the reduction of ROS generation, and the deficiency of Rac1 promoted this function. Actually, recent studies have demonstrated that TZD PPAR- $\gamma$ agonists including pioglitazone affected the generations of ROS and nitrite by inhibiting COX-2 and iNOS expressions, which both are considered to be important sources of the deleterious radicals [15-18]. Therefore, our findings not only confirmed the antioxidative actions of pioglitazone but also advanced the understanding of underlying mechanism that the anti-pyroptic effects of pioglitazone is involved in by reducing ROS production as well as inhibiting Rac1 activity.

Additionally, high-mobility group box (HMGB) 1, a nonhistone DNA-binding protein, has been identified as a proinflammatory mediator and received particular attention with respect to its pathological role in cerebral ischemia [45, 46]. High levels of serum HMGB-1 were observed in patients with stroke compared with healthy individuals [25]. Extracellular HMGB-1 released from damaged or necrotic tissues acts as an endogenous danger signal. The pro-inflammatory effect of HMGB-1 depends on the translocation of HMGB-1 from nucleus to cytoplasm and its release into the extracellular space [47]. The receptor for advance glycation endproducts (RAGE) is a transmembrane innate immune receptor and the activation of this receptor plays an important role in mediating pro-inflammatory effects [48]. The interaction between RAGE and its ligand HMGB-1 results in the activation of mitogen-activated protein kinase (MAPK) and nuclear factor NF-kB/p53 signaling pathway that mediates the production of a variety of pro-inflammatory cytokines [26, 27]. However, up to now, there have been no previous studies to determine whether pioglitazone ameliorates ischemic injury through its HMGB-1/RAGE inhibitory mechanism in ischemic stroke. In vitro and in vivo evidences in this present study showed that pioglitazone notably alleviated cytoplasmic translocations of HMGB-1 and RAGE, compared with control and vehicle groups. We further investigated the molecular mechanism of pioglitazone's PPAR- $\gamma$-mediated inhibition of HMGB-1/RAGE, and demonstrated that GW9662 could block pioglitazone-mediated downregulation in cytoplasmic translocations of HMGB-1 and RAGE, suggesting that PPAR- $\gamma$ dependent pathway may be involved in pioglitazone's inhibition of HMGB-1/RAGE activation. Actually, Marx et al. had demonstrated that pioglitazone reduced RAGE expression in human endothelial cells, thus limiting the cells' susceptibility toward proinflammatory effects [49]. Pioglitazone prominently also down-regulated RAGE expression and inhibited high glucoseinduced increased in ROS production and NF-kB activation in coronary artery smooth muscle cells (SMCs) [50]. On the other hand, a recent study reported that HMGB-1, acting through RAGE, initiated a cascade of cellular and molecular events, including pyroptosome formation and caspase-1 activation [51]. Therefore, our research discovered a new signaling pathway of pioglitazone's activation of PPAR- $\gamma$ that attenuated brain pyroptosis under ischemia/reperfusion conditions. However, until now, there is fewer papers to indicate possible interplay between HMBG-1/RAGE and Rac1/ROS. A previous published paper had shown that an anticancer drug, bleomycin (BLM) is able to trigger cancer cell death via its capacity to induce ROS-mediated liberation of HMBG-1, demonstrating that ROS formation is necessary for HMBG-1 release [52].

In brief, our findings provided the first evidence that cerebral pyroptosis resulted from ischemia reperfusion injury is alleviated by pioglitazone because of its inhibitory effects on HMGB-1/RAGE and Rac1/ROS activation by activating PPAR- $\gamma$ (Fig. 7). The findings in this study proved the essential role of pioglitazone in cerebral ischemia injury and greatly contributed to our understanding of the inhibitory role of pioglitazone on pyroptosis in ischemic stroke.

\section{Acknowledgements}

This work was supported by the National Natural Science Foundation of China (grant 81771422).

\section{Disclosure Statement}

The authors declare that they have no Disclosure Statement.

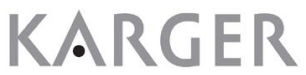




\section{Cellular Physiology Cell Physiol Biochem 2018;45:2351-2368 \begin{tabular}{l|l} 
and Biochemistry Published online: March 16, 2018 & $\begin{array}{l}\text { (c) } 2018 \text { The Author(s). Published by S. Karger AG, Basel } \\
\text { www.karger.com/cpb }\end{array}$
\end{tabular}}

Xia et al.: Pioglitazone Protected Against Pyroptosis by Activating PPAR- $\gamma$

\section{References}

1 Selim M: Perioperative stroke. N Engl J Med 2007;356:706-713.

2 Sun Z, Yue Y, Leung CC, Chan MT, Gelb AW, Study Group for Perioperative Stroke In C: Clinical diagnostic tools for screening of perioperative stroke in general surgery: a systematic review. Br J Anaesth 2016;116:328-338.

3 Chen CX, Huang J, Tu GQ, Lu JT, Xie X, Zhao B, Wu M, Shi QJ, Fang SH, Wei EQ, Zhang WP, Lu YB: NAMPT inhibitor protects ischemic neuronal injury in rat brain via anti-neuroinflammation. Neuroscience 2017;356:193-206.

4 Han B, Lu Y, Zhao H, Wang Y, Li L, Wang T: Electroacupuncture modulated the inflammatory reaction in MCAO rats via inhibiting the TLR4/NF-kappaB signaling pathway in microglia. Int J Clin Exp Pathol 2015;8:11199-11205.

-5 Maltez VI, Tubbs AL, Cook KD, Aachoui Y, Falcone EL, Holland SM, Whitmire JK, Miao EA: Inflammasomes Coordinate Pyroptosis and Natural Killer Cell Cytotoxicity to Clear Infection by a Ubiquitous Environmental Bacterium. Immunity 2015;43:987-997.

6 Tan MS, Tan L, Jiang T, Zhu XC, Wang HF, Jia CD, Yu JT: Amyloid-beta induces NLRP1-dependent neuronal pyroptosis in models of Alzheimer's disease. Cell Death Dis 2014;5:e1382.

7 Chang W, Lin J, Dong J, Li D: Pyroptosis: an inflammatory cell death implicates in atherosclerosis. Med Hypotheses 2013;81:484-486.

8 Liu Z, Gan L, Xu Y, Luo D, Ren Q, Wu S, Sun C: Melatonin alleviates inflammasome-induced pyroptosis through inhibiting NF-kappaB/GSDMD signal in mice adipose tissue. J Pineal Res 2017;63.

-9 Chen H, Lu Y, Cao Z, Ma Q Pi H, Fang Y, Yu Z, Hu H, Zhou Z: Cadmium induces NLRP3 inflammasomedependent pyroptosis in vascular endothelial cells. Toxicol Lett 2016;246:7-16.

10 Karmakar M, Katsnelson M, Malak HA, Greene NG, Howell SJ, Hise AG, Camilli A, Kadioglu A, Dubyak GR, Pearlman E: Neutrophil IL-1beta processing induced by pneumolysin is mediated by the NLRP3/ASC inflammasome and caspase-1 activation and is dependent on K+ efflux. J Immunol 2015;194:1763-1775.

11 Yang JR, Yao FH, Zhang JG, Ji ZY, Li KL, Zhan J, Tong YN, Lin LR, He YN: Ischemia-reperfusion induces renal tubule pyroptosis via the CHOP-caspase-11 pathway. Am J Physiol Renal Physiol 2014;306:F75-84.

-12 Wu H, Huang T, Ying L, Han C, Li D, Xu Y, Zhang M, Mou S, Dong Z: MiR-155 is Involved in Renal IschemiaReperfusion Injury via Direct Targeting of FoxO3a and Regulating Renal Tubular Cell Pyroptosis. Cell Physiol Biochem 2016;40:1692-1705.

13 Bordet R, Ouk T, Petrault O, Gele P, Gautier S, Laprais M, Deplanque D, Duriez P, Staels B, Fruchart JC, Bastide M: PPAR: a new pharmacological target for neuroprotection in stroke and neurodegenerative diseases. Biochem Soc Trans 2006;34:1341-1346.

14 Culman J, Nguyen-Ngoc M, Glatz T, Gohlke P, Herdegen T, Zhao Y: Treatment of rats with pioglitazone in the reperfusion phase of focal cerebral ischemia: a preclinical stroke trial. Exp Neurol 2012;238:243-253.

15 Pereira MP, Hurtado O, Cardenas A, Alonso-Escolano D, Bosca L, Vivancos J, Nombela F, Leza JC, Lorenzo P, Lizasoain I, Moro MA: The nonthiazolidinedione PPARgamma agonist L-796, 449 is neuroprotective in experimental stroke. J Neuropathol Exp Neurol 2005;64:797-805.

-16 Collino M, Aragno M, Mastrocola R, Benetti E, Gallicchio M, Dianzani C, Danni O, Thiemermann C, Fantozzi R: Oxidative stress and inflammatory response evoked by transient cerebral ischemia/reperfusion: effects of the PPAR-alpha agonist WY14643. Free Radic Biol Med 2006;41:579-589.

17 Zhao Y, Patzer A, Herdegen T, Gohlke P, Culman J: Activation of cerebral peroxisome proliferator-activated receptors gamma promotes neuroprotection by attenuation of neuronal cyclooxygenase- 2 overexpression after focal cerebral ischemia in rats. FASEB J 2006;20:1162-1175.

18 Shimazu T, Inoue I, Araki N, Asano Y, Sawada M, Furuya D, Nagoya H, Greenberg JH: A peroxisome proliferator-activated receptor-gamma agonist reduces infarct size in transient but not in permanent ischemia. Stroke 2005;36:353-359.

19 Pistrosch F, Passauer J, Herbrig K, Schwanebeck U, Gross P, Bornstein SR: Effect of thiazolidinedione treatment on proteinuria and renal hemodynamic in type 2 diabetic patients with overt nephropathy. Horm Metab Res 2012;44:914-918.

-20 Yuan Y, Zha H, Rangarajan P, Ling EA, Wu C: Anti-inflammatory effects of Edaravone and Scutellarin in activated microglia in experimentally induced ischemia injury in rats and in BV-2 microglia. BMC Neurosci 2014;15:125. 


\section{Cellular Physiology Cell Physiol Biochem 2018;45:2351-2368

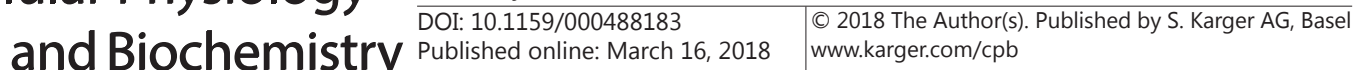

21 Raz L, Zhang QG, Zhou CF, Han D, Gulati P, Yang LC, Yang F, Wang RM, Brann DW: Role of Rac1 GTPase in NADPH oxidase activation and cognitive impairment following cerebral ischemia in the rat. PLoS One 2010;5:e12606.

22 Liao J, Ye Z, Huang G, Xu C, Guo Q, Wang E: Delayed treatment with NSC23766 in streptozotocin-induced diabetic rats ameliorates post-ischemic neuronal apoptosis through suppression of mitochondrial p53 translocation. Neuropharmacology 2014;85:508-516.

-23 Johanna GV, Fredy CA, David VC, Natalia MV, Angel CR, Patricia CG: Rac1 activity changes are associated with neuronal pathology and spatial memory long-term recovery after global cerebral ischemia. Neurochem Int 2010;57:762-773.

-24 Zhang QG, Wang R, Han D, Dong Y, Brann DW: Role of Rac1 GTPase in JNK signaling and delayed neuronal cell death following global cerebral ischemia. Brain Res 2009;1265:138-147.

-25 Schulze J, Zierath D, Tanzi P, Cain K, Shibata D, Dressel A, Becker K: Severe stroke induces long-lasting alterations of high-mobility group box 1. Stroke 2013;44:246-248.

26 Palumbo R, De Marchis F, Pusterla T, Conti A, Alessio M, Bianchi ME: Src family kinases are necessary for cell migration induced by extracellular HMGB1. J Leukoc Biol 2009;86:617-623.

-27 Karuppagounder V, Arumugam S, Thandavarayan RA, Pitchaimani V, Sreedhar R, Afrin R, Harima M, Suzuki H, Nomoto M, Miyashita S, Suzuki K, Nakamura M, Watanabe K: Modulation of HMGB1 translocation and RAGE/NFkappaB cascade by quercetin treatment mitigates atopic dermatitis in NC/Nga transgenic mice. Exp Dermatol 2015;24:418-423.

-28 Chen KB, Uchida K, Nakajima H, Yayama T, Hirai T, Rodriguez Guerrero A, Kobayashi S, Ma WY, Liu SY, Zhu P, Baba H: High-mobility group box-1 and its receptors contribute to proinflammatory response in the acute phase of spinal cord injury in rats. Spine (Phila Pa 1976) 2011;36:2122-2129.

29 Ye Z, Wang N, Xia P, Wang E, Yuan Y, Guo Q: Delayed administration of parecoxib, a specific COX-2 inhibitor, attenuated postischemic neuronal apoptosis by phosphorylation Akt and GSK-3beta. Neurochem Res 2012;37:321-329.

-30 Longa EZ, Weinstein PR, Carlson S, Cummins R: Reversible middle cerebral artery occlusion without craniectomy in rats. Stroke 1989;20:84-91.

-31 Zhu H, Zhang Y, Shi Z, Lu D, Li T, Ding Y, Ruan Y, Xu A: The Neuroprotection of Liraglutide Against Ischaemiainduced Apoptosis through the Activation of the PI3K/AKT and MAPK Pathways. Sci Rep 2016;6:26859.

-32 Ye Z, Li Q, Guo Q, Xiong Y, Guo D, Yang H, Shu Y: Ketamine induces hippocampal apoptosis through a mechanism associated with the caspase-1 dependent pyroptosis. Neuropharmacology 2018;128:63-75.

33 Ye Z, Wang N, Xia P, Wang E, Liao J, Guo Q: Parecoxib suppresses CHOP and Foxo1 nuclear translocation, but increases GRP78 levels in a rat model of focal ischemia. Neurochem Res 2013;38:686-693.

34 Pan Y, Wang N, Xia P, Wang E, Guo Q Ye Z: Inhibition of Rac1 ameliorates neuronal oxidative stress damage via reducing Bcl-2/Rac1 complex formation in mitochondria through PI3K/Akt/mTOR pathway. Exp Neurol 2018;300:149-166.

-35 Silverstein JH, Timberger M, Reich DL, Uysal S: Central nervous system dysfunction after noncardiac surgery and anesthesia in the elderly. Anesthesiology 2007;106:622-628.

-36 Chen X, Zhang X, Wang Y, Lei H, Su H, Zeng J, Pei Z, Huang R: Inhibition of immunoproteasome reduces infarction volume and attenuates inflammatory reaction in a rat model of ischemic stroke. Cell Death Dis 2015;6:e1626.

-37 Simmons LJ, Surles-Zeigler MC, Li Y, Ford GD, Newman GD, Ford BD: Regulation of inflammatory responses by neuregulin-1 in brain ischemia and microglial cells in vitro involves the NF-kappa B pathway. J Neuroinflammation 2016;13:237.

-38 Bergsbaken T, Fink SL, Cookson BT: Pyroptosis: host cell death and inflammation. Nat Rev Microbiol 2009;7:99-109.

39 Franchi L, Eigenbrod T, Munoz-Planillo R, Nunez G: The inflammasome: a caspase-1-activation platform that regulates immune responses and disease pathogenesis. Nat Immunol 2009;10:241-247.

40 Miao EA, Rajan JV, Aderem A: Caspase-1-induced pyroptotic cell death. Immunol Rev 2011;243:206-214.

41 Delaleu N, Bickel M: Interleukin-1 beta and interleukin-18: regulation and activity in local inflammation. Periodontol 2000 2004;35:42-52.

-42 Nakanishi K, Yoshimoto T, Tsutsui H, Okamura H: Interleukin-18 regulates both Th1 and Th2 responses. Annu Rev Immunol 2001;19:423-474. 


\section{Cellular Physiology Cell Physiol Biochem 2018;45:2351-2368

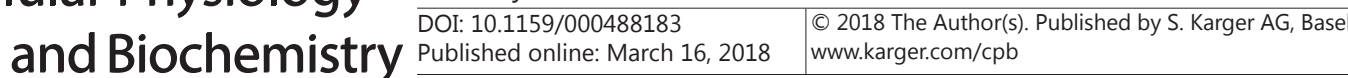

43 Jeyabal P, Thandavarayan RA, Joladarashi D, Suresh Babu S, Krishnamurthy S, Bhimaraj A, Youker KA, Kishore R, Krishnamurthy P: MicroRNA-9 inhibits hyperglycemia-induced pyroptosis in human ventricular cardiomyocytes by targeting ELAVL1. Biochem Biophys Res Commun 2016;471:423-429.

44 Victor NA, Wanderi EW, Gamboa J, Zhao X, Aronowski J, Deininger K, Lust WD, Landreth GE, Sundararajan S: Altered PPARgamma expression and activation after transient focal ischemia in rats. Eur J Neurosci 2006;24:1653-1663.

-45 Qiu J, Nishimura M, Wang Y, Sims JR, Qiu S, Savitz SI, Salomone S, Moskowitz MA: Early release of HMGB-1 from neurons after the onset of brain ischemia. J Cereb Blood Flow Metab 2008;28:927-938.

-46 Nakamura Y, Nakano T, Irie K, Sano K, Tanaka J, Yamashita Y, Satho T, Matsuo K, Fujioka M, Ishikura H, Mishima K: Recombinant human soluble thrombomodulin ameliorates cerebral ischemic injury through a high-mobility group box 1 inhibitory mechanism without hemorrhagic complications in mice. J Neurol Sci 2016;362:278-282.

47 Kalyan S, Chow AW: Staphylococcal toxic shock syndrome toxin-1 induces the translocation and secretion of high mobility group-1 protein from both activated T cells and monocytes. Mediators Inflamm 2008;2008:512196.

48 Wang L, Zhang X, Liu L, Yang R, Cui L, Li M: Atorvastatin protects rat brains against permanent focal ischemia and downregulates HMGB1, HMGB1 receptors (RAGE and TLR4), NF-kappaB expression. Neurosci Lett 2010;471:152-156.

-49 Marx N, Walcher D, Ivanova N, Rautzenberg K, Jung A, Friedl R, Hombach V, de Caterina R, Basta G, Wautier MP, Wautiers JL: Thiazolidinediones reduce endothelial expression of receptors for advanced glycation end products. Diabetes 2004;53:2662-2668.

-50 Di BB, Li HW, Li WP, Shen XH, Sun ZJ, Wu X: Pioglitazone inhibits high glucose-induced expression of receptor for advanced glycation end products in coronary artery smooth muscle cells. Mol Med Rep 2015;11:2601-2607.

-51 Xu J, Jiang Y, Wang J, Shi X, Liu Q, Liu Z, Li Y, Scott MJ, Xiao G, Li S, Fan L, Billiar TR, Wilson MA, Fan J: Macrophage endocytosis of high-mobility group box 1 triggers pyroptosis. Cell Death Differ 2014;21:12291239.

52 Bugaut H, Bruchard M, Berger H, Derangere V, Odoul L, Euvrard R, Ladoire S, Chalmin F, Vegran F, Rebe C, Apetoh L, Ghiringhelli F, Mignot G: Bleomycin exerts ambivalent antitumor immune effect by triggering both immunogenic cell death and proliferation of regulatory T cells. PLoS One 2013;8:e65181. 